\title{
Pseudorandom Noise Impulsive Response Analysis and Aerodynamic Forces of Unmanned Aerial Vehicle Structure
}

\author{
Mohammed D. Salman, Kadim Karim Mohsen*, Aiman Basem Abttan \\ College of Engineering, University of Thi-Qar, Iraq
}

Copyright $\bigcirc 2019$ by authors, all rights reserved. Authors agree that this article remains permanently open access under the terms of the Creative Commons Attribution License 4.0 International License

\begin{abstract}
This paper concentrated about the effect of both the pseudorandom or random vibration (wind waves) and aerodynamic forces on the wing of unmanned aerial vehicle, which brought the attention of specialists in this field during last years, the performance of wing is improved on a definitive solution for the vibration problems which cause failure in the wings of UAV. The distribution of stresses and distortions with aerodynamic loads is studied. Factors such as tension, pressure and shear stress showed on wing of UAVs due to vibration which caused the structure of wing to break down and then failure. The experimental study was carried out by using wing made of composite material (foam and cover by lamination plate), where airfoil type (NACA Clark y) installed inside wind tunnel of low velocity. It is found that the vibration acceleration at constant wind velocity with variation of attack angle of the wing, it is obtained the relationship between the acceleration and the frequency using the LABVEIW program which analyzed and identified the distribution of forces on the wing. The stress concentration areas is created and found under failure occurs, the aerodynamic force, torsion torque and magnitude of deformation is calculated. It is concluded that the close areas from the root wing (fixed end) is most likely to collapse or break.
\end{abstract}

Keywords UAV, Pseudorandom Vibration, Random Vibration, Aerodynamic Load, Drag and Lift forces

\section{Introduction}

The use of Unmanned Aerial Vehicles (UAV) is increased at present time, it can be used in large application such as the photography, load transfer, crops agricultural and UAV which presented in the research field of airplane (Atkins, 2018, Jweeg et al., 2018). There are many types of
UAV: Target and decoy, Reconnaissance, Combat, Research, development, Civil and Commercial UAVs (Prabhu et al., 2015). The primary manufacturing of structures materials was by using aluminum for aircraft and space craft construction (Goh et al., 2017, Finn et al., 2017). Today, structural weight and stiffness requirements have exceeded the capability of conventional aluminum, and high-performance payloads have demanded extreme thermo-elastic stability in the aircraft design environment (Prabhu et al., 2015). Composite materials with continuous fibers are the most suitable option especially (polymer matrix composites reinforced) because of the requirements that must be provided in structure of UAVs, where must be high-strength and lightweight (Sethunathan et al., 2016, Splichal et al., 2015), these composites are reflected in the UAV industry. In this paper the vibrations generated in the wing of UAVs as a result of wind waves is presented. The most vitality of the irregular vibration waves begins from the wind such as, pseudorandom vibration and random vibration is moved which is non-deterministic, this means that behavior in the future response will be absolutely unexpected. The arbitrariness is a normal for the excitation or info, not the mode shapes or characteristic frequencies (Komzsik, 2016). The turbulent wind flow is a forced function which passed over the UAV wing (see figure 1). Moreover, the turbulent pressure at certain points on the wing differs in a random way over time (Samson et al., 2018, Naudascher, 2017). When consider the UAV wing to be a single-degree-of-freedom system, the wing will be vibrating in a sinusoidal manner under the excitation of certain effects and then allows to vibrating freely. The turbulent of wind seems to force the wing to undergo a random vibration response (Wirth et al., 2017, Goud et al., 2014).

The airplanes fly due to generating the lift force by the wings. This force is always reversing the weight of the airplane, where it is always trying to lift the plane to the top (Zhang and Sun, 2018). When the wind passes around the 
wings, the wings change the direction of the wind (see figure 2). The wing is a distinctive design has the ability to create the force capable of lifting the airplane, the cross section of the wing (airfoil) takes a certain shape, where the bottom surface is concave and the top surface will be convex longer than the bottom surface of the wing. The lift is generated primarily by pushing the wings of the airplane for the wind passing to the bottom; the response of wind pushing the wing to the top, also the drag force is reacted or resisted by the structure of the airplane against the thrust force generated by the engine (Li et al., 2018, Yusoff et al., 2015). According to the third law of the motion coined by the Newton states that: For each action, there is an equal and opposite reaction (ISAAC, 2017). In this case, the wings push the wind to the downward, while the wind pushing the wings to the upwards is the reaction, which causes the lift force of the airplane. The lift and drag forces is controlled by changing the angle of the wing or the so-called angle of attack; it is the angle between the chord line of the wing and the stream of wind passing.

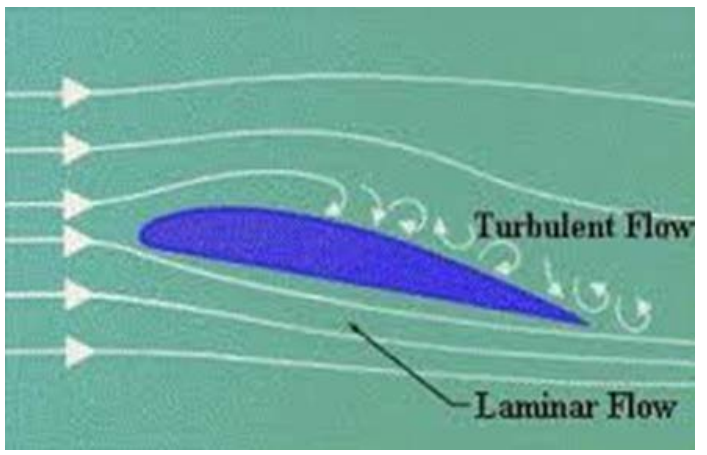

Figure 1. Turbulent flow of wind that passes around the wing

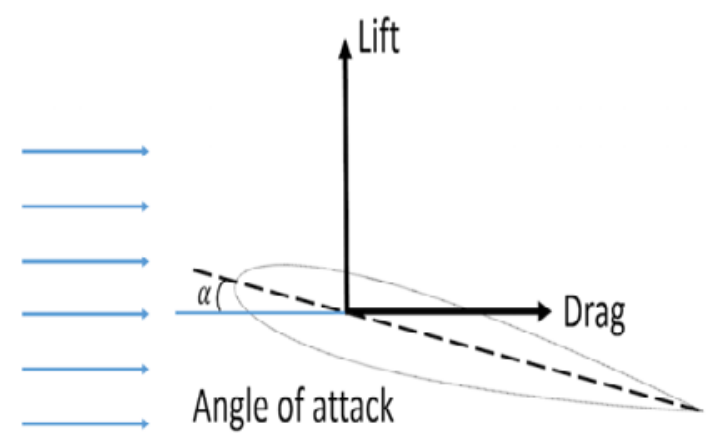

Figure 2. Aerodynamic force

Abid-Aun, (Jweeg et al., 2018), studied numerically the static analysis of the wing with $(M=0.7)$ for taper wing and $(\mathrm{M}=0.2)$ for rectangle wing. ANSYS package is used to obtain the stress distribution on the surface of wing, also the aerodynamic parameters computed by using CFD method which simulated wing loading on wings. The aerodynamic loads on the wing of unmanned aerial vehicle with three attack angles $\left(0^{\circ}, 5^{\circ}\right.$ and $\left.10^{\circ}\right)$ and $(\mathrm{M}=0.4)$ Mach number stated numerically. Results showed that the maximum stress occurs at distance of $0-15 \%$ from the edge of wing by using software program (ANSYS11). it used pressure distribution on the wing to know the distribution of tension and displacement of the structure of the wing (Marqués, 2017, Tischler, 2018).

Recently, Nguyen and co-workers (Triet et al., 2015), have presented theoretically the modeling and simulation of operations in the computational fluid dynamic problem (CFD) on the wing of the plane by using NACA 2412 airfoil at different velocity from 0 to $50 \mathrm{~m} / \mathrm{s}$. Their results were analyzed using ANSYS Structural to determine the lift and drag forces and by using ANSYS Fluent, the pressure and velocity distribution was obtained on the wing surface. Verification was performed by comparing the numerical results with the theoretical results. The results of the comparison showed a good consensus. This model can therefore be used in experimental design in the future.(Asthana et al., 2016, Rao, 2017) analyzed numerically, evaluation and optimization of the structural behavior for the wing of airplane. It focused on reducing the mass and volume of the stresses and deformations that occurs in the plane structure. It is best to keep constant for both the standard sample and the new model. The wing analysis was maintained in relation to structure and stress analysis as well as of aerodynamics.

The main purpose of this paper is to study the overall behavior for the structure of unmanned aerial vehicle with the wind waves. Through, the vibration acceleration and the stresses distribution on the structure of the UAV wing was studied with difference wind velocity and angle of attack.This work also illustrates the aerodynamic forces on the wing surface.

\section{General Model Description}

The sizes of the selected UAV for studied are as shown in figure (3). Manufacturing material of the studied model is the fuselage from foam with cover fiber glass and the wings from foam with cover lamination plate. Mechanical properties of the manufacturing material were founded by using tensile test. From this test it was found the maximum load and force at yield point, through the values of loads, change in length, area and the original length of the sample was calculated stress and strain at the yield point $\left(\mathrm{F}_{\mathrm{y}}=46 \mathrm{~N}\right.$, $\sigma_{\mathrm{y}}=8.518 \mathrm{Mpa}$ and $\varepsilon_{\mathrm{y}}=0.023$ ), also at maximum point $\left(F_{\max }=74 \mathrm{~N}, \sigma_{\max }=13.7 \mathrm{Mpa}, \varepsilon_{\max }=0.1718\right)$ and obtained the modulus of elasticity $\mathrm{E}=386.84 \mathrm{Mpa}$. 


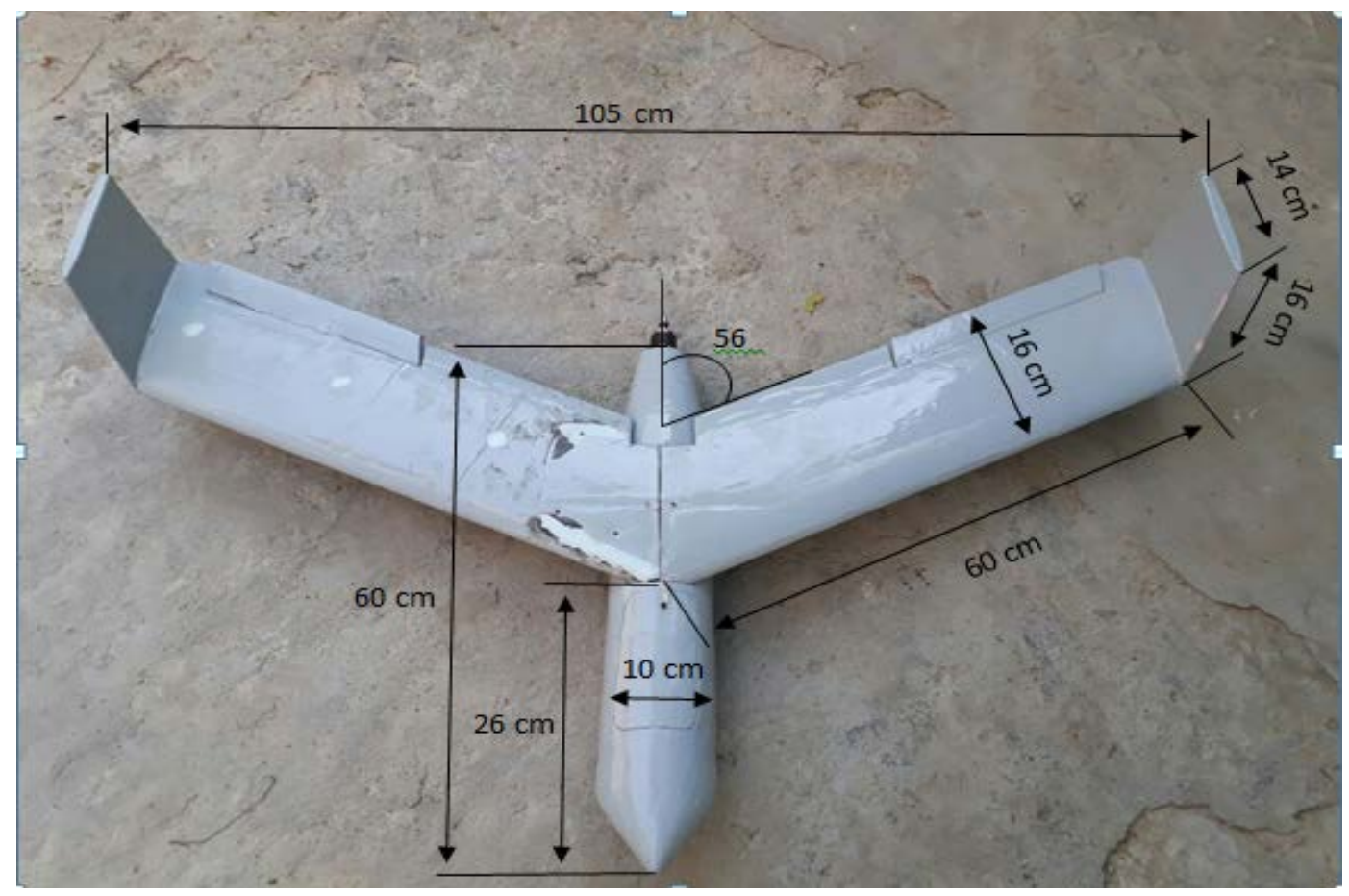

Figure 3. Model parts that have been manufactured

\section{Experimental Model}

The model that was used in the experimental work was the UAV which was manufactured. The model was installed inside low velocity wind tunnels shown figure (4). Wind tunnel test is used to support many major development processes involving aerodynamics, where it is a research tool developed to assist with studying the effects of wind moving over or around solid objects such as aircraft, helicopters, cars, trains, and laboratory research, so it provides the engineers with valuable data on scale models.
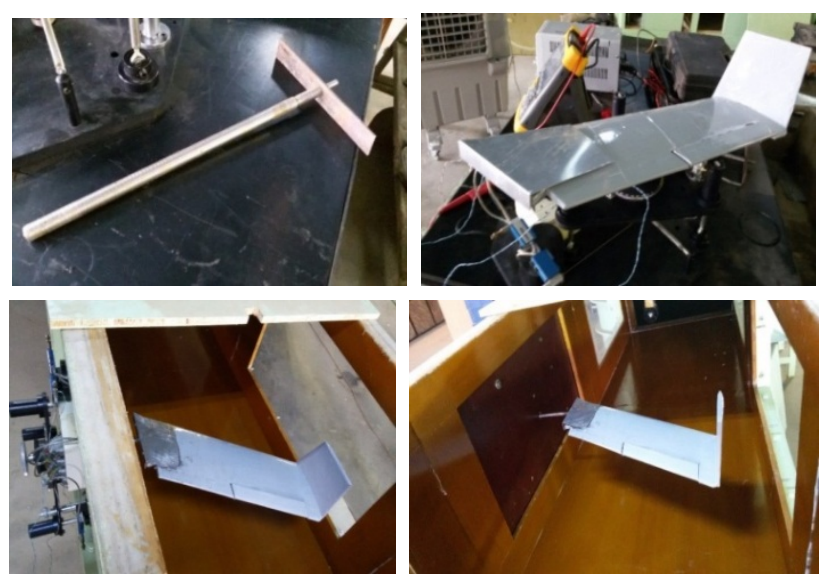

Figure 4. Method of installing the test model inside wind tunnel

The devices that were used in this test:

1- Flow meter used for measurement the wind velocity.

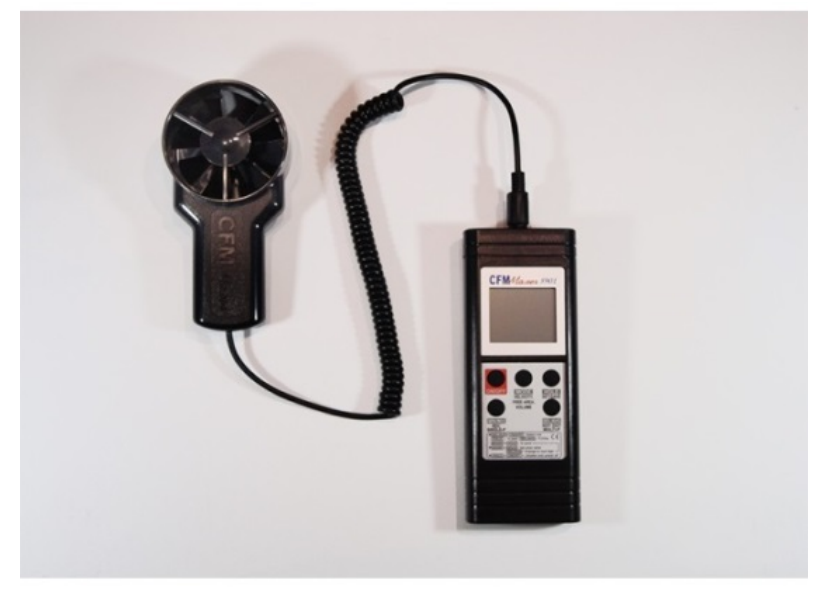

Figure 5. Flow meter device

2- Vibration measurement device (Ni national instrument vibration system) used for resaving and analysis the signals from the sensors.

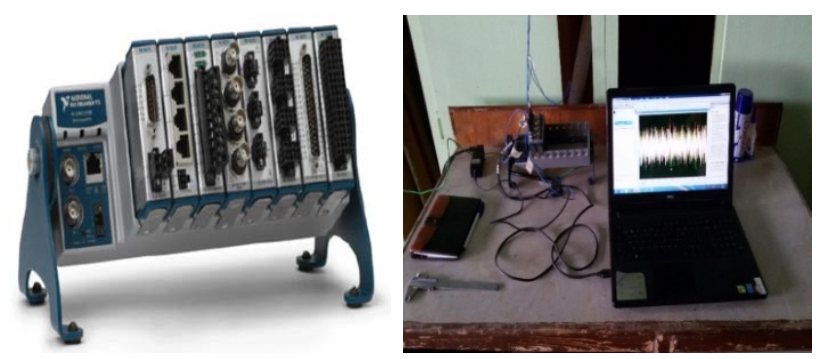

Figure 6. Vibration measurement device 
3- four sensor type of (peso electronic one dimension accelerometer) to obtained the results through four sensors installed at specific locations on the wing surface, where the first sensor $\left(\mathrm{S}_{1}\right)$ was pasted in the middle of the fin at the end of the wing, while the remaining sensors were pasted in the upper surface of the wing in the middle and at the distance $(52 \mathrm{~cm}, 35$ $\mathrm{cm}$ and $18 \mathrm{~cm}$ ) for $S_{2}, S_{3}$ and $S_{4}$ respectively.
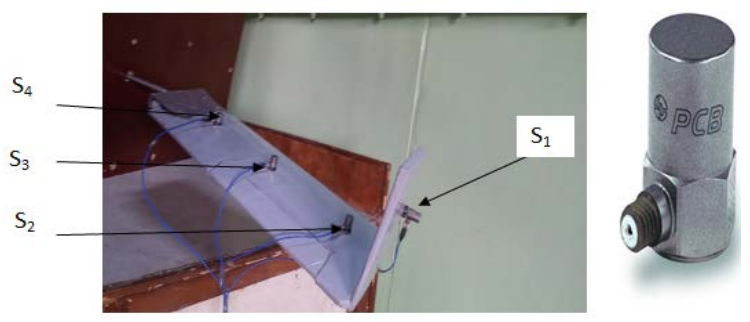

Figure 7. Sensors devices

4- Aerodynamic measurement device [Airfoil wind (Lift, Falt and Drag forces measurement)] used for calculated the aerodynamic variable such as lift and drag forces and torque.

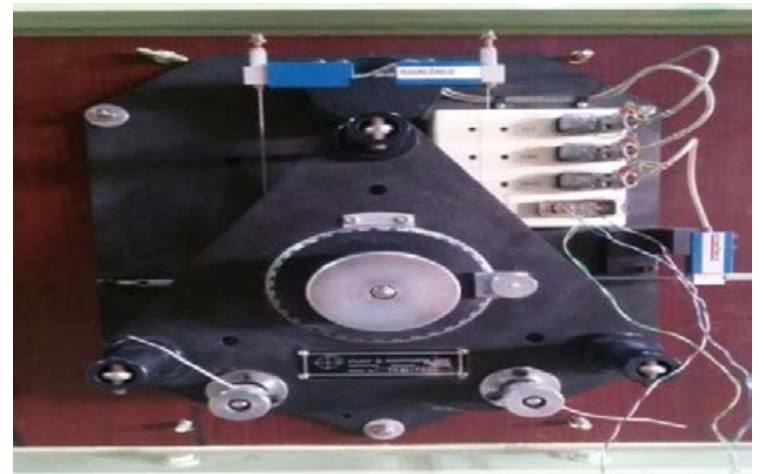

Figure 8. Aerodynamic measurement device

Through this work, the variation of vibration acceleration is calculated with the time history (real time) produced by pseudo random excitation (wind waves) at same time for the wing when was installed inside wind tunnel vibration acceleration and aerodynamics forces were analyzed at difference Reynolds number (wind velocity) with variation angle of attack $\left(0^{\circ}, 5^{\circ}, 10^{\circ}, 15^{\circ}\right.$ and $20^{\circ}$ ), and its relationship with the change and stress concentration areas (areas prone to failure).

\section{Results and Discussions}

\subsection{Vibration Analysis}

Pseudorandom noise or any irregular wave is often produced by random wind movement. Wind waves are considered the input units of the system used in the test. The wing was installed inside the wind tunnel and after achieving the maximum speed at which the wind tunnel used in the test can reach. The test was done by changing the attacking angle of the wing and recorded the readings by the sensors that have been established as mentioned in this research, it was obtained the vibration amplitude and vibration velocity and acceleration of vibration and after through the use of the program (LAB VEIW) through the Fast Fourier Transform (FFT) method was obtained the relationship between the acceleration and frequency through which we can know the distribution the air forces and its focus areas along the wing. The variation of acceleration (force per unit mass) with frequency at attack angle of $0^{\circ}$ for all sensors is shown in figure (9). From this figure it can be seen that for all sensors the period from 5 $\mathrm{Hz}$ to $5000 \mathrm{~Hz}$ is disturbance. Also it can be found that the maximum values of acceleration was recorded at $110 \mathrm{~Hz}$, where for $S_{1}, S_{2}, S_{3}$ and $S_{4}$ the values were $0.42 \mathrm{~m} / \mathrm{s}^{2}, 0.19$ $\mathrm{m} / \mathrm{s}^{2}, 0.072 \mathrm{~m} / \mathrm{s}^{2}$ and $0.31 \mathrm{~m} / \mathrm{s}^{2}$ respectively.
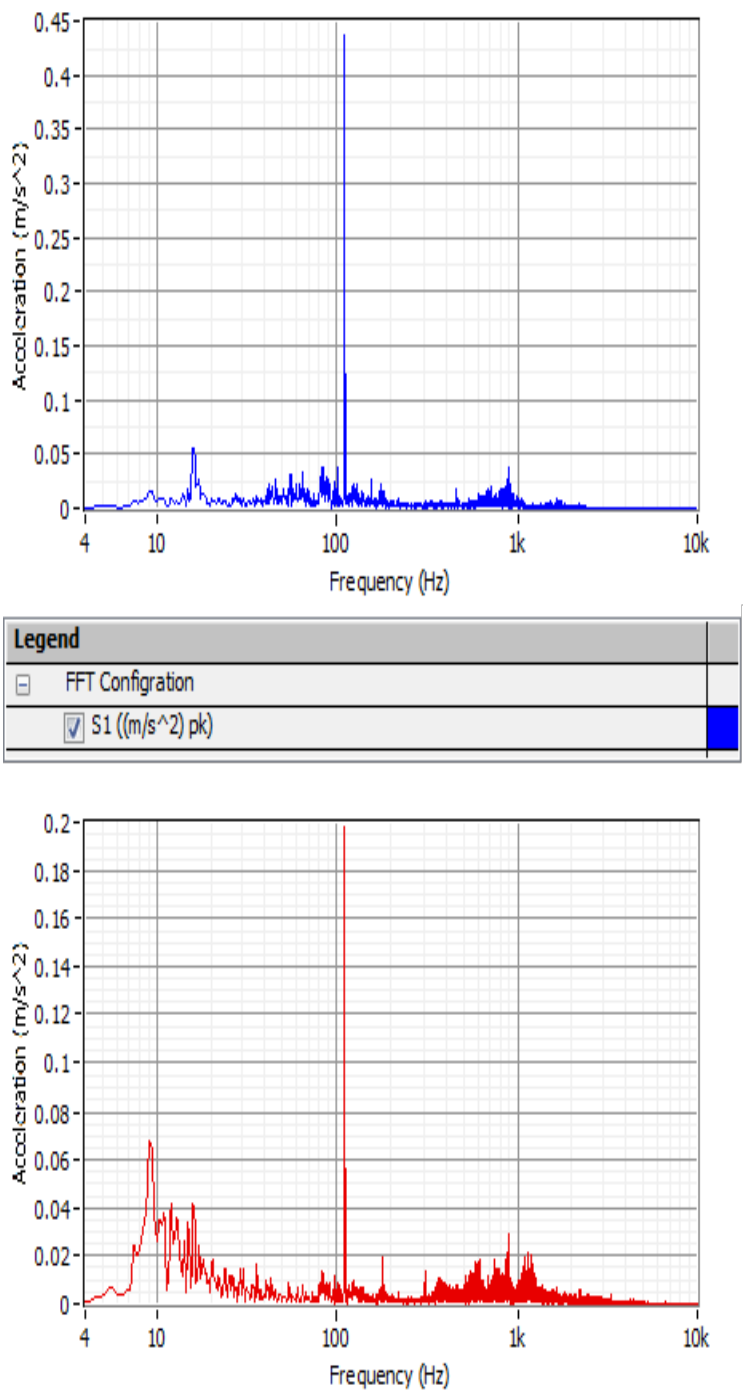

\begin{tabular}{l|l|}
\hline Legend & \\
\hline$\boxminus \quad F F T$ Configration & \\
\hline$\nabla S 2\left(\left(\mathrm{~m} / \mathrm{s}^{\wedge} 2\right) \mathrm{pk}\right)$ & \\
\hline
\end{tabular}



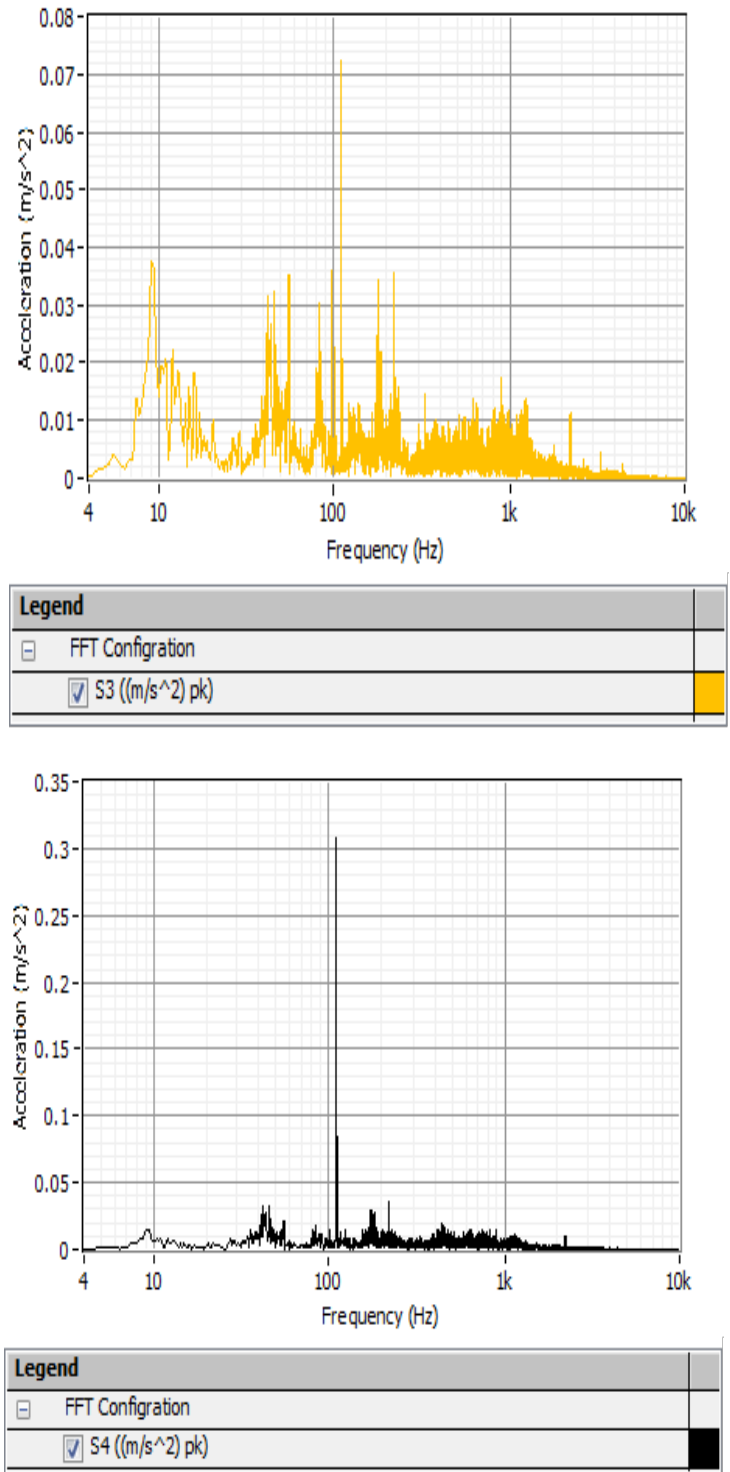

Figure 9. Relationship between the acceleration of vibration (the force per unit mass) and the frequency for all sensors at angle of attack $\left(0^{\circ}\right)$

Figure (10) illustrates the variation of acceleration with frequency at attack angle of $5^{\circ}$. It can be noted increasing the disturbance in this case, where value of acceleration for all sensor ranged between $\left(0.03 \mathrm{~m} / \mathrm{s}^{2}, 0.04 \mathrm{~m} / \mathrm{s}^{2}\right.$ and 0.05 $\left.\mathrm{m} / \mathrm{s}^{2}\right)$ during the period $(5 \mathrm{~Hz}, 5000 \mathrm{~Hz})$ and reaches maximum values for $S_{1}, S_{3}$ and $S_{4}$ at period $110 \mathrm{~Hz}$ are $\left(0.105 \mathrm{~m} / \mathrm{s}^{2}, 0.0425 \mathrm{~m} / \mathrm{s}^{2}\right.$ and $\left.0.06 \mathrm{~m} / \mathrm{s}^{2}\right)$, either $S_{2}$ maximum value of acceleration is $\left(0.0425 \mathrm{~m} / \mathrm{s}^{2}\right)$ at $55 \mathrm{~Hz}$.

Figure (11) presents the variation of acceleration with frequency at attack angle of $10^{\circ}$. It can be shown that the vibration behavior and accelerometer values did not change significantly. The recorded acceleration values for all sensors ranged between $\left(0.02 \mathrm{~m} / \mathrm{s}^{2}, 0.03 \mathrm{~m} / \mathrm{s}^{2}, 0.04 \mathrm{~m} / \mathrm{s}^{2}\right.$ and $0.05 \mathrm{~m} / \mathrm{s}^{2}$ ), also reached $0.07 \mathrm{~m} / \mathrm{s}^{2}$ during different periods of frequency between $(5 \mathrm{~Hz}$ and $5000 \mathrm{~Hz}$ ). The maximum acceleration values recorded during this procedure, where the value was for $S_{1}\left(0.089 \mathrm{~m} / \mathrm{s}^{2}\right)$ at 110
$\mathrm{Hz}$ and $\mathrm{S}_{2}\left(0.037 \mathrm{~m} / \mathrm{s}^{2}\right)$ during $9 \mathrm{~Hz}$, either the sensors $\mathrm{S}_{3}$ and $\mathrm{S}_{4}$ were maximum values $\left(0.08 \mathrm{~m} / \mathrm{s}^{2}, 0.085 \mathrm{~m} / \mathrm{s}^{2}\right)$ respectively during the period $42 \mathrm{~Hz}$.
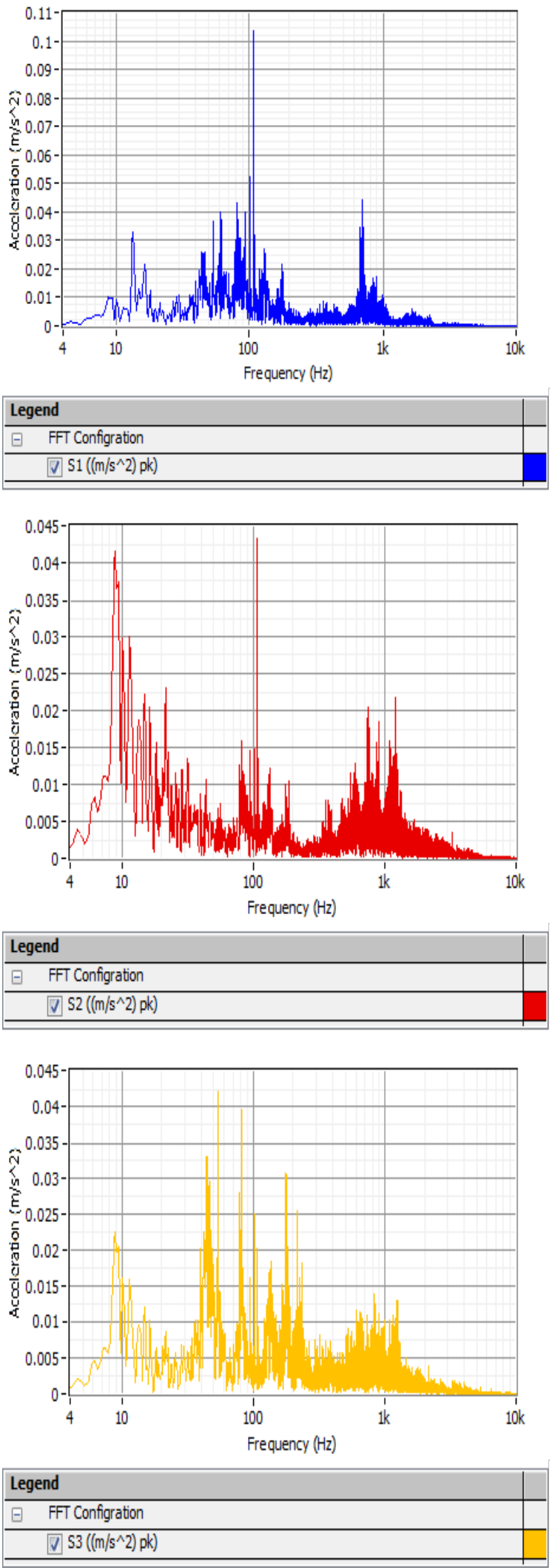

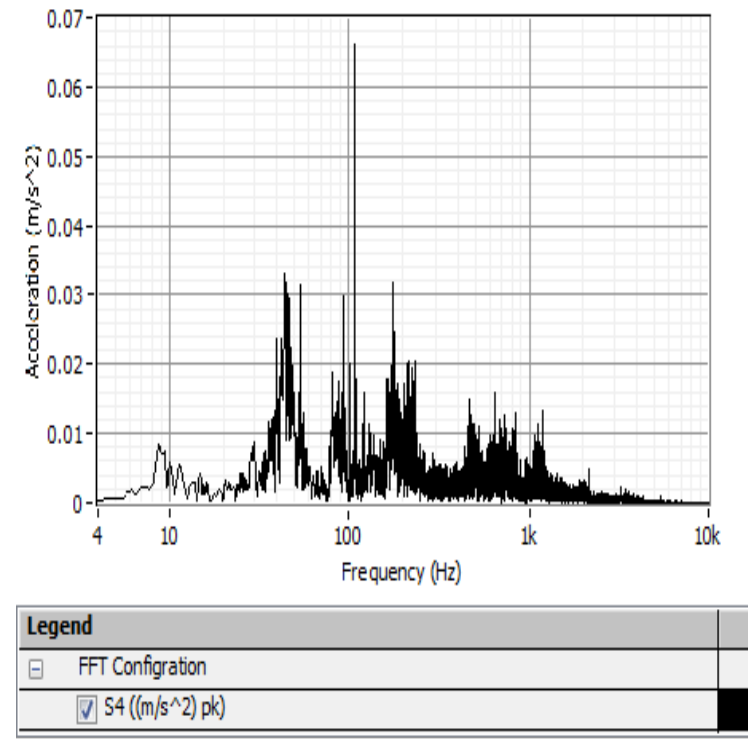

Figure 10. Relationship between the acceleration of vibration (the force per unit mass) and the frequency for all sensors at angle of attack ( $\left.5^{\circ}\right)$
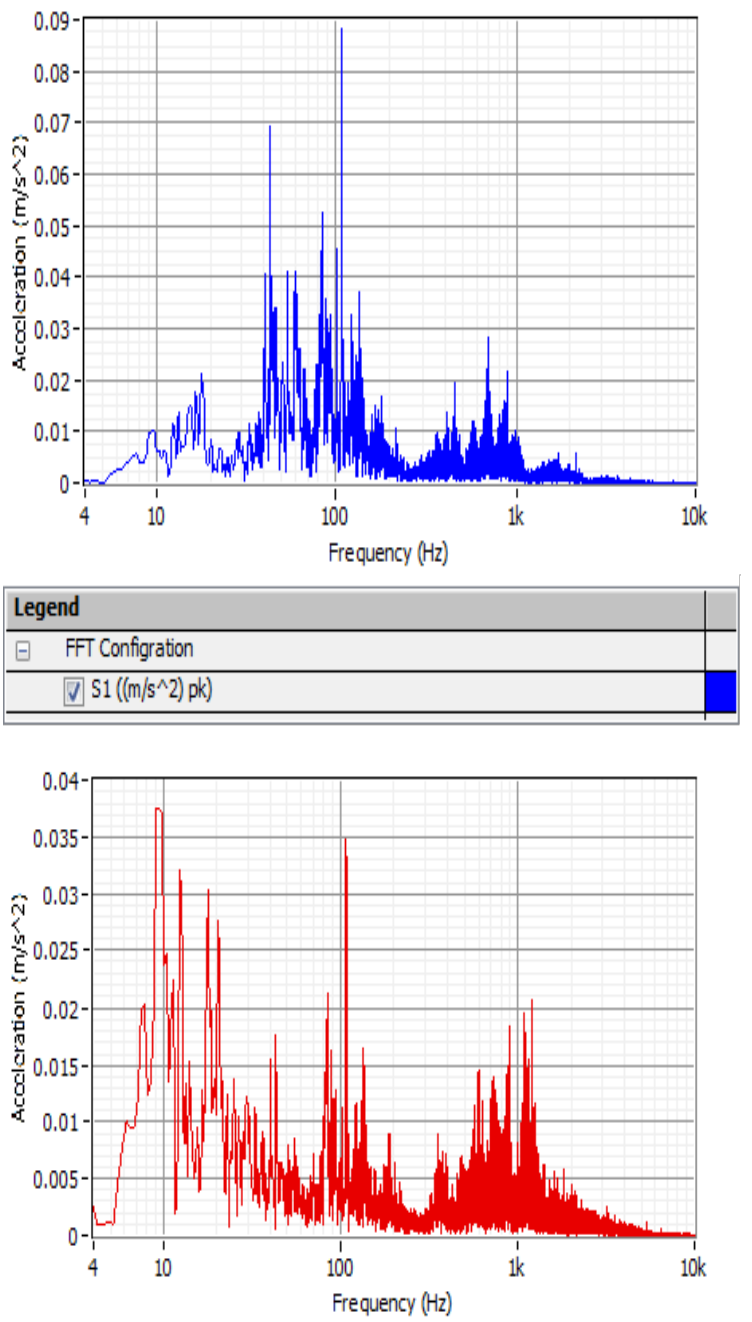

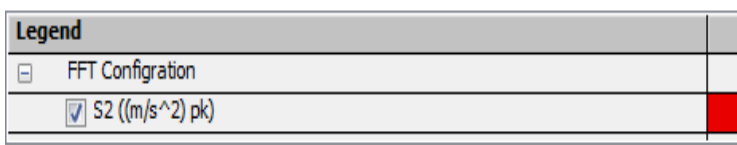
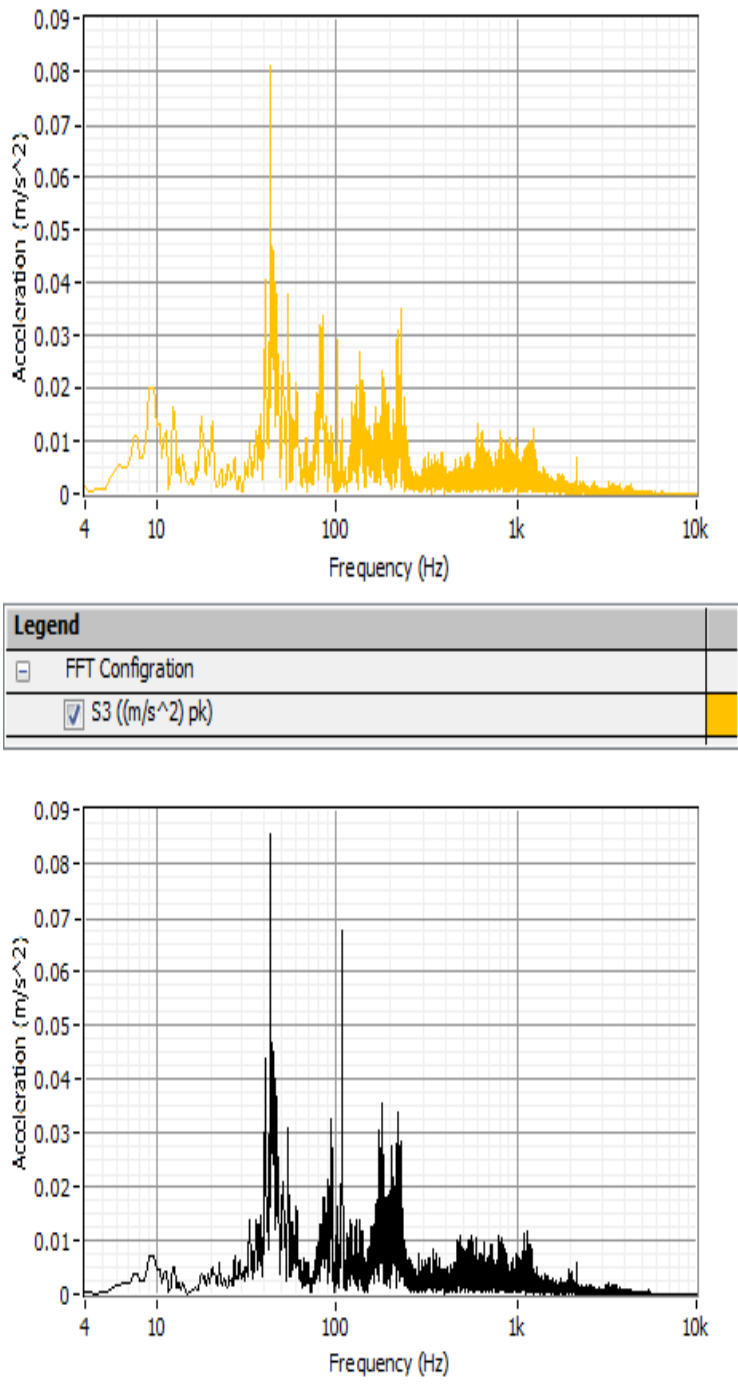

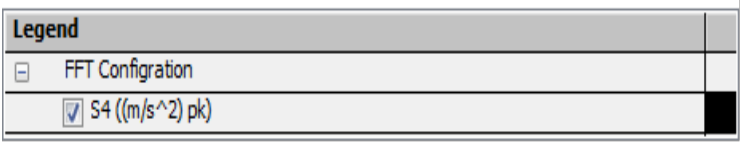

Figure 11. Relationship between the acceleration of vibration (the force per unit mass) and the frequency for all sensors at angle of attack $\left(10^{\circ}\right)$

Figure (12) observes the variation of acceleration with frequency at attack angle of $15^{\circ}$.It can be observed that the disturbance and vibration behavior in this angle has increased significantly, where the acceleration value ranged between $\left(0.01 \mathrm{~m} / \mathrm{s}^{2}\right.$ to $\left.0.1 \mathrm{~m} / \mathrm{s}^{2}\right)$ for all sensors. The maximum acceleration values were recorded at $110 \mathrm{~Hz}$ for $\mathrm{S}_{1}, \mathrm{~S}_{2}$ and $\mathrm{S}_{4}$ were $0.425 \mathrm{~m} / \mathrm{s}^{2}, 0.19 \mathrm{~m} / \mathrm{s}^{2}$ and $0.3 \mathrm{~m} / \mathrm{s}^{2}$ respectively, either the maximum value for S3 was 0.096 $\mathrm{m} / \mathrm{s}^{2}$ at $44 \mathrm{~Hz}$.

Figure (13) shows the variation of acceleration with frequency at attack angle of $20^{\circ}$. From this figure can be observed the decrease in the acceleration values in the case and all the sensors except $\mathrm{S}_{3}$ record the same values of the previous situation almost. The acceleration values in this case fluctuated between $\left(0.01 \mathrm{~m} / \mathrm{s}^{2}\right.$ to $\left.0.09 \mathrm{~m} / \mathrm{s}^{2}\right)$ during the process, the maximum value for $S_{1} 0.12 \mathrm{~m} / \mathrm{s}^{2}$ at period 16 

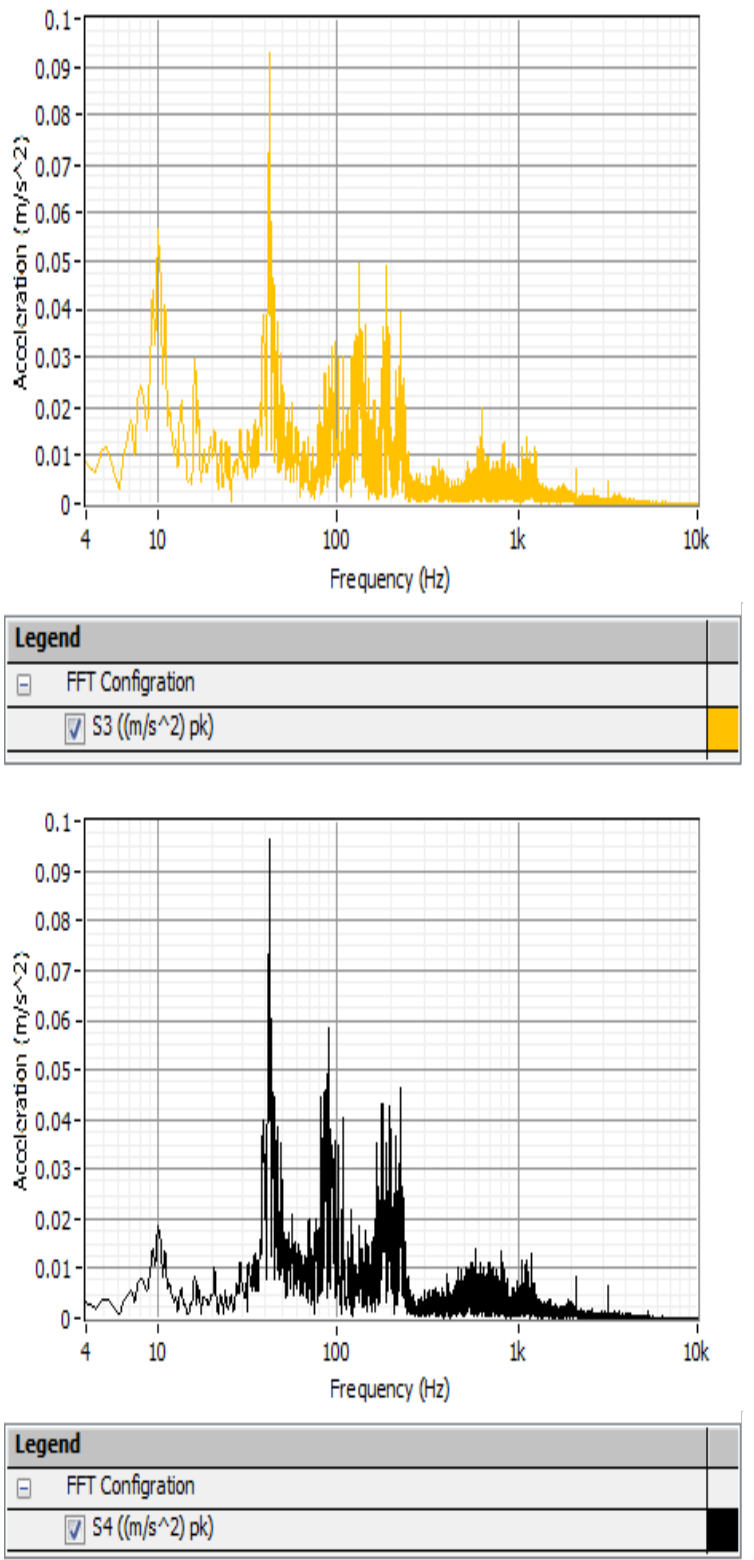

Figure 13. Relationship between the acceleration of vibration (the force per unit mass) and the frequency for all sensors at angle of attack $\left(20^{\circ}\right)$

\subsection{Aerodynamic Analysis}

After the completion of the first part of the test (the part of the calculation of vibrations and their effect on the structure of the model used), the forces of aerodynamics were found through the use of the device to find the aerodynamic forces affecting on UAV, where it was calculated the lift and drag forces and torque and the amount of deformation in the wing through the change wind velocity and angle of attack. The variation of the lift and drag forces and torque and deformation magnitude with angle of attack at $\operatorname{Re}=885743.055$ is shown in figure (14). From this figure it can be seen that the drag force (D), lift force (L), torque (T)and deformation (y) are starting from zero except the drag force starting from non-zero in this case from $(1.32 \mathrm{~N})$, the reason is that the lift force and the torque are generated from the result of changing angle of attack either the force of clouds affect the wing because it is generated by the impedance shown by the structure to resist the wind waves, also note that all variables change directly proportional with change the angle of attack. The maximum value in this case $\left(\mathrm{D}_{\max }=15.226 \mathrm{~N}, \mathrm{~L}_{\max }=21.51\right.$ $\mathrm{N}, \mathrm{T}_{\max }=2.15 \mathrm{~N} \cdot \mathrm{m}$ and $\mathrm{y}_{\max }=28 \mathrm{~mm}$ ).

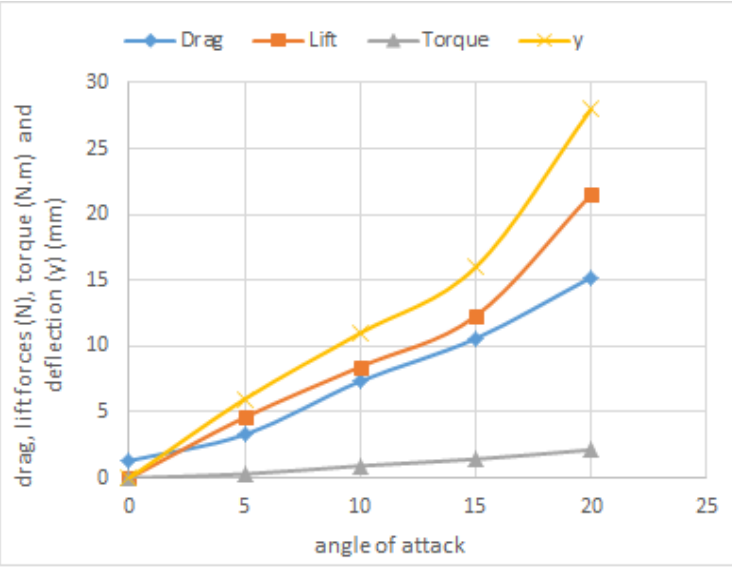

Figure 14. Relationship between the drag, lift forces, torque and deformation magnitude $(y)$ with variation the angle of attack at $(\mathrm{Re}=$ 885743.055)

Figure (15) illustrates the variation of the lift and drag forces and torque and deformation magnitude with angle of attack at $\mathrm{Re}=978979.1667$. It can be noted that all the variable values increased with the increase of wind velocity; also it can see that the drag force in this case started from $(1.65 \mathrm{~N})$. Maximum values for all variables in this case increased with increasing wind velocity, where it became $\left(\mathrm{D}_{\max }=15.95 \mathrm{~N}, \mathrm{~L}_{\max }=25.35 \mathrm{~N}, \mathrm{~T}_{\max }=2.21 \mathrm{~N} \cdot \mathrm{m}\right.$ and $\mathrm{y}_{\max }=33 \mathrm{~mm}$ ).

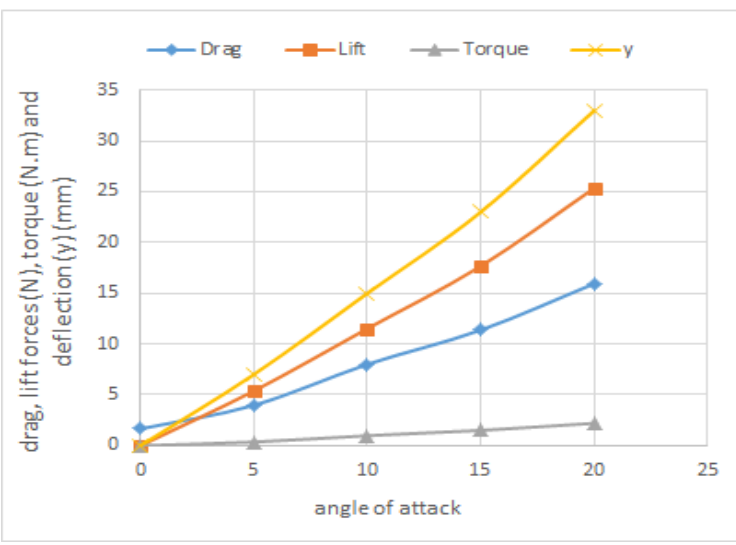

Figure 15. Relationship between the drag, lift forces, torque and deformation magnitude (y) with variation the angle of attack at ( $R e$ $=978979.1667$ )

Figure (16) presents the variation of the lift and drag forces and torque and deformation magnitude with angle of attack at $\operatorname{Re}=1025597.222$. It can be shown that the gradually increase in the values of all the forces affecting the wing with increased wind speed more clearly. In this 
case the drag force started from $(1.72 \mathrm{~N})$. The maximum values in this case have increased as they become $\left(\mathrm{D}_{\max }=\right.$ $16 \mathrm{~N}, \mathrm{~L}_{\max }=28.42 \mathrm{~N}, \mathrm{~T}_{\max }=2.34 \mathrm{~N} . \mathrm{m}$ and $\mathrm{y}_{\max }=37 \mathrm{~mm}$ ).

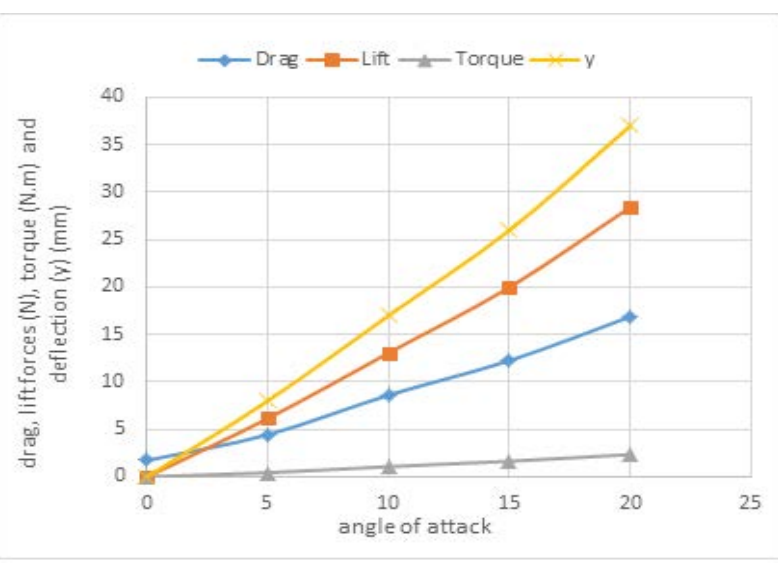

Figure 16. Relationship between the drag, lift forces, torque and deformation magnitude (y) with variation the angle of attack at (Re $=1025597.222$ )

Figure (17) observes the variation of the lift and drag forces and torque and deformation magnitude with angle of attack at $\mathrm{Re}=1072215.27$. The behavior of the change for all variables can be illustrated. Also, the drag forces is less than the lift force and for all the cases, because the attack angles of the wing are positive, the wing is in the takeoff mode, so increasing the angle of the attack will increase the effect of the lifting force more than the effect of the drag force. In this case the force of the clouds starts from (1.80 $\mathrm{N})$ and the maximum values become $\left(\mathrm{D}_{\max }=17.67 \mathrm{~N}, \mathrm{~L}_{\max }\right.$ $=30.73 \mathrm{~N}, \mathrm{~T}_{\max }=2.46 \mathrm{~N} \cdot \mathrm{m}$ and $\mathrm{y}_{\max }=40 \mathrm{~mm}$ ).

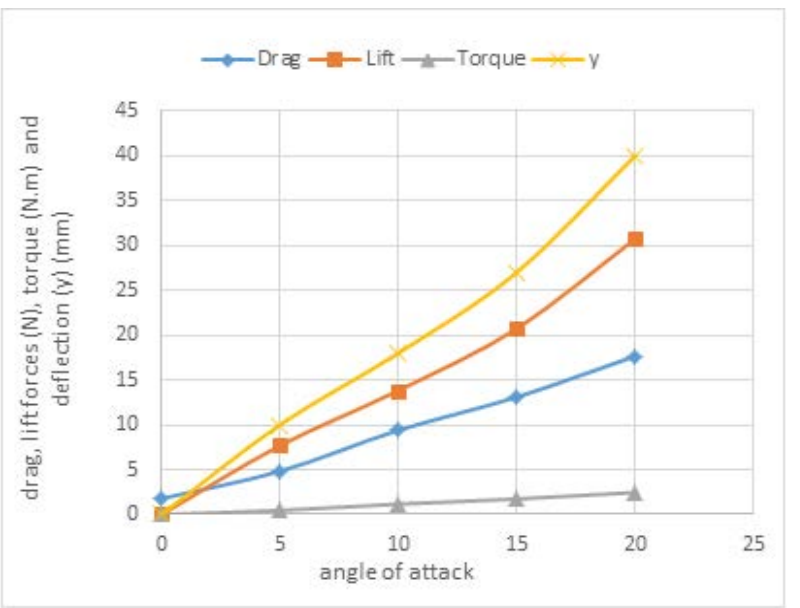

Figure 17. Relationship between the drag, lift forces, torque and deformation magnitude (y) with variation the angle of attack at (Re $=1072215.27$ )

\section{Conclusions}

Due to the great development in the field of aeronautics and the use of UAVs, Where it was held a pilot study of the effect of random wind waves on the wing of a drone with the change of the angle of attack to know the distribution of forces on the wing surface and determine areas of failure. From the experimental results obtained in the present work, the following remarks can be concluded:

1) The maximum of vibration accurse at the fin of wing.

2) The loads Concentration at reign near from the fixed end.

3) Failure or fracture occurs in the wing at the distance $18 \mathrm{~cm}$ from the fixed end.

4) Vibration behavior is similar for each sensor with a change the angle of attack.

5) The highest values of vibration acceleration at the angle of attack $15^{\circ}$ and the lowest values at $5^{\circ}$.

6) With increasing the angle of attack all studied parameters (lift and drag force, torque and deformation) increased for all selected velocity.

7) For all selected velocity value of drag force is started from $1.3 \mathrm{~N}$.

\section{Acknowledgements}

This research was supported/partially supported by university of Thi-Qar, Engineering Collage. We grateful to the researchers from mechanical department who provided insight and expertise that greatly assisted the research

\section{REFERENCES}

[1] E. M. Atkins, "Aerospace Engineering Curricular Expansion in Information Systems," in Advances in Aeronautical Informatics, ed: Springer, 2018, pp. 135-151.

[2] M. J. Jweeg, A. P. D. S. J. AL, and A. L. S. H. Abid-Aun, "Optimization of Light Weight Aircraft Wing Structure," JOURNAL OF ENGINEERING AND SUSTAINABLE DEVELOPMENT, vol. 12, pp. 1-22, 2018.

[3] M. Prabhu, J. N. Raj, and G. Vignesh, "Optimization of unmanned aerial vehicle wing structure," IJISET-International Journal of Innovative Science, Engineering \& Technology, vol. 2, pp. 28-34, 2015.

[4] G. Goh, S. Agarwala, G. Goh, V. Dikshit, S. Sing, and W. Yeong, "Additive manufacturing in unmanned aerial vehicles (UAVs): challenges and potential," Aerospace Science and Technology, vol. 63, pp. 140-151,2017.

[5] A. Finn, K. Rogers, F. Rice, J. Meade, G. Holland, and P. May, "A Comparison of Vertical Atmospheric Wind Profiles Obtained from Monostatic Sodar and Unmanned Aerial Vehicle-Based Acoustic Tomography," Journal of Atmospheric and Oceanic Technology, vol. 34, pp. 2311-2328, 2017.

[6] P. Sethunathan, M. Seeman, M. Uthayakumar, and G. Manimaran, "STATIC AND DYNAMIC ANALYSIS ON ENVIRONMENTAL CONTROL SYSTEM OF REHEATER ATTACHMENT FOR A TYPICAL NAVAL FIGHTER AIRCRAFT," International Journal of Advances 
in Engineering \& Technology, vol. 9, p. 153, 2016.

[7] J. Splichal, A. Pistek, and J. Hlinka, "Dynamic tests of composite panels of an aircraft wing," Progress in Aerospace Sciences, vol. 78, pp. 50-61, 2015.

[8] L. Komzsik, What every engineer should know about computational techniques of finite element analysis: CRC Press, 2016.

[9] M. Samson, T. Monnet, A. Bernard, P. Lacouture, and L. David, "Analysis of a swimmer's hand and forearm in impulsive start from rest using computational fluid dynamics in unsteady flow conditions," Journal of biomechanics, vol. 67, pp. 157-165, 2018.

[10] E. Naudascher, Hydrodynamic Forces: IAHR Hydraulic Structures Design Manuals 3: Routledge, 2017.

[11] N. Wirth, P. Bayrasy, B. Landvogt, K. Wolf, F. Cecutti, and T. Lewandowski, "Analysis and Optimization of Flow Around Flexible Wings and Blades Using the Standard Co-simulation Interface MpCCI," in Recent Progress in Flow Control for Practical Flows, ed: Springer, 2017, pp. 283-321.

[12] T. S. K. Goud, A. S. Kumar, and S. S. Prasad, "Analysis of fluid-structure interaction on an aircraft wing," Analysis, vol. 3, pp. 146-152, 2014.

[13] L. Zhang and C. Sun, "Simulation Analysis of Fluid-Structure Interaction of High Velocity Environment Influence on Aircraft Wing Materials under Different Mach Numbers," Sensors, vol. 18, p. 1248, 2018.
[14] X. Li, W. Wang, Y. Tang, L. Wang, T. Bai, F. Zhao, et al., "Research on Gliding Aerodynamic Effect of Deformable Membrane Wing for a Robotic Flying Squirrel," Journal of Bionic Engineering, vol. 15, pp. 379-396, 2018.

[15] Yusoff, M. Abdullah, M. Abdul Mujeebu, and K. Ahmad, "Effect of skin flexibility on aerodynamic performance of flexible skin flapping wings for micro air vehicles," Experimental Techniques, vol. 39, pp. 11-20..2015

[16] S. ISAAC, PHILOSOPHIAE NATURALIS PRINCIPIA MATHEMATICA: FORGOTTEN BOOKS, 2017.

[17] P. Marqués, "Advanced UAV Aerodynamics, Flight Stability and Control: An Introduction," Advanced UAV Aerodynamics, Flight Stability and Control: Novel Concepts ,Theory and Applications, p. 1, 2017.

[18] M. B. Tischler, "System identification methods for aircraft flight control development and validation," in Advances in Aircraft Flight Control, ed: Routledge, 2018, pp. 35-69.

[19] N. M. Triet, N. N. Viet, and P .M. Thang, "Aerodynamic analysis of aircraft wing," VNU Journal of Science: Mathematics-Physics, vol. 31, 2015.

[20] K. Asthana, A. Jameson, S. Lele, and P. Pinsky, "Analysis and Design of Optimal Discontinuous Finite Element Schemes," Stanford University.2016,

[21] S. S. Rao, The finite element method in engineering: Butterworth-heinemann, 2017. 